\title{
System Failure for Good Reasons? Understanding Aid Information Management Systems (AIMS) with Indonesia as State Actor in the Changing Field of Aid
}

\author{
Kyung Ryul Park ${ }^{1}$ and Boyi $\mathrm{Li}^{2}$ \\ ${ }^{1}$ London School of Economics, London, UK, k.park5@1se.ac.uk \\ ${ }^{2}$ University of Exeter, Exeter, UK, b.li@exeter.ac.uk
}

\begin{abstract}
Information systems (IS) failure in developing countries has been often understood as the failure of development practitioners to think and act in accordance with the local context. Such explanatory accounts mostly take contingency as the situation in the local context in which multiple stakeholders can coordinate and adapt to the local. There is a lack of understanding of contingency as the global context of the international development field, in particular how IS failure can be shaped by the state actor. In this paper, we trace the change of the global aid governance that influenced the context of aid information management systems (AIMS) in Indonesia. We argue that understanding the failure of AIMS in Indonesia needs to move from the project's local situation to the global-level, recursive relationship between the field of aid governance and the state actor. Interpreting AIMS failure as the result of Indonesia's strategic agency in the shifting landscape of global aid agenda allows information communication and technology and development (ICTD) researchers to reflect upon the macro political economy of development, in particular how the emerging powers can shape the development agenda in which future ICT innovations unfold.
\end{abstract}

Keywords. ICTD, information systems failure, aid information management systems (AIMS), Indonesia, recursive contingency

\section{$1 \quad$ Introduction}

Many studies have been conducted to explain the failures of information systems (IS) in developing countries [7,28,31]. One of the main challenges, according to Heeks [22], can be described as the problem of the "design-actuality" gap. In ICTD literature, this is associated with the theorizing efforts to understand the local context in its recursive relations with ICT interventions [3,4], constituting a growing body of knowledge to address the gap between system design and local contingency $[2,8]$. State actors, in this context, are widely seen as the indispensable intermediary in translating and coordinating multiple stakeholders' expectations and actions [1,14]. System failure in the field of ICTD has been predominantly framed as a microsituational struggle to bring together multiple stakeholders and to generate a contingent fit between local use and the dominant logic of the field of international devel- 
opment $[21,25]$. Such explanatory accounts mostly take contingency as the local or domestic context in which a developing country coordinates multiple domestic interpretations and objectives on the recipient side. There is a lack of understanding of contingency in the macro context of international development, in particular how IS failure can be shaped by the state actor as an agency in the field of global aid . Indeed, foreign aid is such an established field where the relationship between donor and recipient countries is subject to historically evolved rules, governance, tensions, and cultural dispositions, which jointly define a distinctive organizational field [12]. The success or failure of IS has rarely been explained by examining state actor in the context of an organizational field. Moreover, understanding the role of state actor in global context bears the key to explaining those particular cases of failure where the major sources of contingency are to be found on the donor's side instead of the recipient's [32,36]. This is often associated with what Heeks [22] referred to as "sustainability failure", in which IS initiatives were initially successful in developing countries but subsequently abandoned after a short period of time. Much of the disuse of IS needs to be explained by tracing the changes in relations, ideologies, and institutional arrangements among the donors and international organizations (IOs), which are normally beyond the influence of state actors in the context of developing countries. Contingency in the global field of aid has rarely been accounted for and theorised in ICTD literature to explain system failure.

In this paper, we aim to understand why a donor-funded information system, aid information management systems (AIMS) designed to institute aid principles outlined in the Paris Declaration on Aid Effectiveness (PD), was implemented, used, and then abandoned in Indonesia. It is theoretically significant because it illustrates a specific case of "sustainability failure" in a struggle with contingency as the change of relations, rules, and understandings in the global field of aid. By tracing the justifications for the failure of AIMS from its local context to the global context, we illustrate how an IS failure in Indonesia needs to be seen as the result of macro events occurring in the global field of aid and how the state of Indonesia has actively shaped this globallevel contingency, which used to be dominated by the West. Through this case, we demonstrate an emerging situational gap in what is referred to as "recursive contingency" [11], in which the Indonesian state seizes opportunities to find an alternative legitimacy to justify the 'failure'. The state actor can be clearly seen in this recursive contingency as the dominant logic of institutions is challenged by the state. We suggest that this new understanding of contingency presents a unique opportunity for the use of new theoretical lens to examine system failure in developing country.

\section{The Global Field of Aid: Governance and Institutional Power}

\subsection{Paris Declaration and Institutionalization of the Field}

Based on a plethora of research and international calls for effective aid, a series of international forums in the 2000s shaped a new framework known as 'aid effectiveness'. In particular, the OECD DAC built significant momentum to improve aid effec- 
tiveness and reached a major milestone, namely the endorsement of the PD in 2005 [33]. The Declaration was endorsed by 138 countries and 28 IOs in the Second High Level Forum (HLF) on Aid Effectiveness, and may be the most authoritative principle and practical roadmap to improve aid quality, imposing commitments to share aid information for enhanced transparency and coordination [33]. Based on the assumption of transaction cost theory and result-oriented approach, five principles are suggested: ownership, alignment, harmonization, results, and mutual accountability. The PD was often criticized for the challenges to achieving goals in practice [38], its technocratic orientation, and conflicting or misleading principles [20], and the lack of involvement of non-DAC emerging donors and CSOs. However, the PD was still influential in creating powerful political momentum to reorganize the way recipient countries and development partners cooperate. In addition, through the Accra Agenda for Action (AAA) endorsed at the third HLF in Ghana in 2008, the OECD tried to incorporate feedback and suggest a more recipient-focused action plan. Building on the PD, AAA highlights sharing aid information as the most fundamental action to be achieved as a prerequisite of better transparency, coordination and aid effectiveness.

\subsection{Information Systems in Aid Management}

The use of information systems in the public sector has been widely discussed as an innovative tool for the process of information rationalization. Envisioned by the new public management (NPM), ICT adoption in the public sector in developing countries was expected to enhance transparency [6], increase efficiency [42], improve service delivery [24], and improve interaction with citizens [41]. In the aid effectiveness debate, information systems are perceived as an innovative tool to enable stakeholders to enhance aid coordination and transparency [17], and help recipient governments plan and predict their budgets better, taking more ownership in aid coordination mechanism. With this backdrop, a number of ICT applications commonly referred to as AIMS have been implemented in developing countries over the past two decades. As a generic term, "AIMS includes websites or databases that store and process aid information on donors' activities, budgets, and development indicators" [35]. The PD may be the most significant momentum for the global adoption of AIMS which has been largely supported by major donors [35]. In spite of significant attention given to such systems and the heavy investment made, many cases have not achieved the expected outcomes that the rhetoric of AIMS promised, and even failed to reach sustainability [35].

\section{Recursive Contingency and Institutional Change}

If practice theories provide a broad avenue to make sense of the recursive relationship between structure and agency, current theoretical approaches prevalent in ICTD structuration theory, actor network theory, activity theory, etc - are mostly focused on the micro-situational actions of individual and organizational actors, and their unfolding relations with technological artefacts. This paper develops an understanding of 
practice theories by defining contingency as macro situations in which state actors are being governed by, and purposefully negotiating the global institutions; and state actors, have the practical, evaluative agency to interpret the "dilemmas, and ambiguities of presently evolving situations" [13]. We maintain that ICTD field can benefit from shedding light on the macro perspectives which view state as a constructive member of the international aid community with specific, strategic concerns about its status and prestige in power relations with other states, where the recursive relationship between state actor and global institutions are put into the central fora of enquiries. The agency of the Indonesian state can be seen in its efforts to negotiate with the institutions of aid, which frames the meanings and justification of implementing the AIMS ant its eventual shutdown. Such framings of ICTD projects as the practical, strategic agency of the state actor concerning its position and power on global stage of institutions constitutes the essential novelty of theoretical contributions that we are trying to make.

According to this school of practice theory, institutional structures are reproduced by the actors who accept the set of norms, rules, and cultural understandings as the dominant logic of institutions [39] while collectively changing the structures through actions $[18,37]$. The theory of recursive contingency aims to address the situations where established institutional structures become unstable and the possibility of a deinstitutionalisation process is real $[11,26]$. It refers to the institutional change scenarios in which certain events take place and cannot be interpreted and categorized by applying existing dominant logic of institutional structures. The incapability of codifying these events usually leads to two divergent consequences: either the actors improvise a new set of codes that become recognized and accepted as the legitimate means of understanding, or the actors find alternative schemes of codification that potentially de-stabilize the dominant institutional logic. Events are defined as scenarios that are "not known, unexpected, and unwelcomed by the 'master planners' or the organizational manageables of dominant institutions" $[9,19]$. When events take place and become knowable by actors, the flexibility of interpreting the meanings of events and the following rhetorical and discursive movements becomes the source of recursivity and contingency.

Once the corresponding relationship between the dominant institutional logic and the emerging practical scenarios becomes decoupled, the alternative possibility becomes open and accessible to actors' practical knowledge, which means the politics of competing for legitimacy of reasoning is unleashed. The legitimacy of the logic is challenged as actors possess alternative, competing means of interpretation to justify different logic of actions and relationship-building. Recursive contingency may not necessarily cause the dominance of the alternative, as the process of recursive constructions of understandings is subject to the process of a competitive game for gaining legitimacy [27]. Yet, it is directly conducive to the de-institutionalisation process in a field [11].

Recursive contingency in the field of aid and development is likely to happen when the leading donors attempt to design and implement information systems in recipient countries with the purpose of setting up a system (such as AIMS with its supporting institutions) to codify aid principles such as aid effectiveness, transparency, and coor- 
dination into the practice guidelines in recipient countries. As an institutional logic, these governance principles correspond to a system of codification schemes that enable actors to make sense of specific situations they encounter in their everyday work. Ideally, the structures of dominant institutions are reproduced by the actors who skillfully and compliantly recognize their daily encounters as codes and translate the meanings into the AIMS that reduce the social complexity into computable forms of data, tables, and texts. In practice, however, users of AIMS may encounter contextspecific situations, scenarios, or cultural phenomena that they find difficult to either translate or simply too complex to reduce to the computable forms of data and tables. Such difficulty leads to two divergent consequences: a) users of AIMS improvise new codes that are consistent with the existing codification schemes and are accepted as part of aid governance structure, or b) users might find alternative codification schemes and translation that belong to different, rival paradigms of interpreting the social reality; in other words, the possibility of a different aid governance structure. Based upon these theoretical propositions, the research question of this paper can framed as: how does Indonesia, as a state actor, find alternative ways of justification and legitimacy to implement and then abandon the AIMS system in the changing field of global aid governance institutions?

\section{$4 \quad$ Methodology}

This research adopts an interpretive single case study design. The purpose of the research is to explore why AIMS fails to achieve in sustainability, and the case study is appropriate strategy of inquiry when the main research questions are 'how' or 'why' to study a phenomenon in its natural setting [43]. Case study methodology has often been used in order to give rich narratives in the field of IS in past decades [40]. For the case selection, we focused on the AIMS category of 'implemented once but abandoned', a case of "sustainability failure" [35]. Among the countries, the Indonesian AIMS was the most interesting, unique and accessible case for the following reasons. First, Indonesia has had multiple experiences in IS implementation for aid management. In 2005, the government implemented the Recovery Aceh Nias (RAN) database with UNDP and ADB financial support in order to manage humanitarian assistance and enhance coordination for post-tsunami recovery. The RAN was used during the recovery period, and was arguably considered a success story by international development agencies [29]. However, the AIMS implemented in 2010, the subject of this study, seems not successful. Second, the IT developer of the case is not one of the major competitors in the global market that was identified [35], but a mix of local IT consultants. Third, as a member of the G20, Indonesia's position in the global field of aid is quite different from other recipient countries. It has been a recipient country, while taking a role of, leading South-South cooperation. This setting provides uniqueness to the case study.

The fieldwork in Indonesia took place of August 2015 to August 2016. From an interpretive epistemology, this study relies interviews, informal conversations, and archival research [15]. Semi-structured interviews were conducted with aid experts in donor agencies and IOs, as well as government officials and the IT experts who de- 
veloped the AIMS. The interviews were generally 1 to 1.5 hours long. During this time several secondary data sources were collected and reviewed that included official project documents, policy briefs, evaluation reports, government regulations, media articles, contracts with IT consultants and technical documents on the AIMS.

\section{Case Study}

\subsection{Aid Governance in Indonesia}

Foreign aid has been an important component of Indonesian domestic politics and economy, and is also considered to be a diplomatic tool for donor countries seeking military, political and economic advantages since the establishment of Indonesia as a nation state [23]. Indonesia's legacy in political and international relations continues to shape the current debate on the national development strategy and to have an influence on its perspective on aid in many ways. Before the 1997 Asian Financial Crisis, foreign aid played a big role in 'budget support' helping the country maintain fiscal stimulation, but making its economy unstable with a very high debt rate. This economic instability forced the authoritarian regime to finally step down and ushered in a new era of democracy. Susilo Bambang Yudhoyono's (SBY) inauguration in 2004 could be viewed as a turning point in terms of the country's development policy and aid management. He declared that Indonesia no longer regarded foreign aid as a financial supplement to domestic resources, but as a national catalyst for enhancing socio-economic development and improving institutional capacity. His administration sought to improve aid governance and to focus on building the capacity of government to effectively manage loans and grants in two ways: 1) the establishment of the National Medium-Term Development Plan (RPJMN) (2004-09 and 2009-14), 2) the issue of regulations including the Government Regulation No. 2/2006 that provides general guidance for decision makers to negotiate with multilateral and bilateral donors.

\subsection{Aid Information Management Systems (AIMS)}

Realizing the importance of an aid effectiveness agenda, the Indonesian government took leadership in establishing the roadmap of a country-specific action plan-the Jakarta Commitment- to bring the PD and the AAA to the national level. The Commitment was signed by 26 development partners in January, 2009, and defines the policy direction towards better aid management and enhanced coordination among stakeholders. Furthermore, the Aid Effectiveness Secretariat (A4DES) was established with the transitional multi-donor fund to provide support in facilitation and coordination of activities to achieve the Commitment. One of the key activities was the implementation of AIMS as a single-window system for monitoring and evaluating aid activities.

Even before 2009, the terms of reference for AIMS had already been developed by the National Development Planning Agency (BAPPENAS) through a series of interim 
meetings and the UNDP-led four-day workshop on 'Effective Aid Management' in October 2008. The BAPPENAS finally received a grant from the German Technical Cooperation Agency (GTZ) and entered into a contract in February, 2010. A series of AIMS coordination meeting was held with diverse stakeholders including BAPPENAS, the Ministry of Finance, the State Secretariat, A4DES, and GTZ. Soon after, the recruitment process was carried out, and four local IT professionals were hired for developing the system. The AIMS was launched in June, 2010 with a description as a national computerized system for long-term aid management. The webbased system was designed to give an overview of loans and grants by geomapping donors' activities and providing a visual presentation and analysis of aid data. However, the short term objective of the AIMS was a computerization of the Survey on Monitoring PD Phase 3 to be done before the Busan HLF in 2011. The national launch of the Survey Phase 3 was held with development partners in November. By late 2012, however, the AIMS was no longer being used, and was subsequently abandoned.

\section{$6 \quad$ Analysis \& Discussion}

Now we analyse the process of AIMS implementation and failure in the narrative of Indonesian state striving for position and power in the reform of aid governance. There are three episodes of major change in the relations and common understanding of aid governance in the global context. As we briefly discussed, the PD of 2005 is a milestone event in the global field of aid that marks a new process of institutionalization, through the establishment of a set of norms and rules rationalizing the concept of aid effectiveness. The process prescribes a set of legitimate principles for governing aid activities, and provides protocols shared by all signatory to coordinate aid efforts. Through a series of meetings, agenda-setting, survey and monitor exercises, these legitimate principles and framework are sufficiently communicated between stakeholders. This communication ensures that the global community shares institutional structures. The institutional work can be clearly seen in the activities such as the Survey on Monitoring PD, and the AAA produced in the third HLF in 2008. The five PD principles and the Survey, are emerging institutional frameworks orchestrated and driven by powerful actors, particularly the OECD DAC countries and IOs. In this institutionalized context, recipient countries are generally expected to accept and practice these codes in managing aid.

\subsection{Episode One: Reluctance (2005-2008)}

In this scenario, the state agency of Indonesia in the context of global aid becomes rather peculiar. Indonesia signed the PD in 2005 but decided not to participate in the first round of the Survey in 2006. Instead, Indonesia established the new Government Regulation NO.2/2006 on Managing Foreign Aid in an effort to institutionalise aid governance and promote aid effectiveness, without being directly involved in and accountable for the PD institutions. In 2007, the Consultative Group on Indonesia 
(CGI), the long-established donor coordination body, was dissolved by President SBY. The move was, however, widely welcomed by domestic media and CSOs. It was viewed as a symbolic event marking the growing independence of Indonesia as a state actor taking full ownership of its own development agenda.

How did Indonesia justify its actions in the sense that it joined the PD in 2005 and yet distanced itself from the actual institutional work prescribed and expected by the PD community? To address this question, one needs to consider the particular "recursive contingency" that the Indonesian state was facing. Such contingency existed because Indonesia was embedded in a situation where two sets of codes were established, namely the PD and the domestic codes. These were created to help to understand the state's challenges with aid governance reform and to justify its actions. The SBY administration signed the PD in acknowledgement of the importance of participating in the global aid agenda. However, it was also evident that Indonesia did not submit to the new institutional regime of the PD in 2006 by resisting the first-round Survey, since the SBY administration opted for the utilization of domestic institutions in the reform of aid governance. In fact, the turn to domestic institutional capacity building to manage aid resonated well the notion of 'independence', which was a historically powerful discourse that generates political credit. Indonesia has been a fast-recovering economy since the Crisis in 1997, and on-track to be recognized as a middle-income country, which meant that 'ownership' of its development agenda was essential for SBY.

The recursivity of contingency can be seen in the efforts of both the Indonesian state and the leading international actors of the PD to understand each other's positions, actions and intentions; and to try to reach an agreement on how to regulate this situation by modifying their policies without undermining the essential principles. There was rising criticism from the international community on the non-participatory behaviour of Indonesia. From Indonesia's perspective, too much criticism risked drifting its commitment, as SBY's cabinet was trying to avoid being seen as submitting to international pressure. Such recursivity was dramatized by an event in 2008 in which Indonesia took the U-turn decision to fully participate in the PD, promising to take the Survey, and to maintain relations with donors under AAA, including the establishment of a new AIMS that had been recommended by the PD and AAA. Given Indonesia's historical preference for independence and ownership, how did this become possible?

\subsection{Episode Two: Compliance and AIMS (2009-2011)}

The AAA in 2008 concluded with a supplementary provision to the PD, on the roles of the recipient government in building domestic institutional capacity. Specifically, the principles of 'ownership' settled and emphasized in AAA highlighted "stronger leadership on aid coordination and more use of country systems for aid delivery" [34]. The implementation of AAA was followed by a full Indonesian endorsement in 2009, during which SBY was re-elected and commenced his second term. In this period of 2008 to 2009 , it is evident that the Indonesian state was actively shaping the agenda of aid governance by finding common ground with the leading actors of the PD as 
well as other emerging economies while attempting to secure the legitimacy to justify its preference for the domestic reform agenda, which emphasizes the discourse of 'independence' and 'international leadership'. In January 2009, Indonesia commissioned the Jakarta Commitment in an effort to implement the AAA principles on a national level. The A4DES was established to support the commitment "to ensure that the government of Indonesia's institutions have the capacity to take full ownership and to lead the aid coordination and aid management processes" (Jakarta Commitment).

The Indonesian AIMS was designed according to AAA principles and Jakarta Commitment in the hopes of better aid coordination and effectiveness. With financial support from GTZ, the AIMS was implemented in BAPPENAS and launched in June, 2010. The BAPPENAS managed AIMS, and led a series of stakeholder meetings and training workshops for data collection from donors. The system was used by donors and the government for completing the Online Survey in 2011. In the establishment of AIMS, we find the convergence of two distinctive codes of sense-making, if possible, whose meanings become simultaneously inscribed into the design of technological systems. The design and use of AIMS, and its attendant, serve to justify the legitimacy of the global aid agenda towards better coordination and effectiveness at the local government level, while strengthening 'stronger leadership' of the government. From the SBY administration's view, the AIMS served to endorse its political campaign for 'independence', while keeping its commitment to the PD process intact. Stability is temporally achieved by the state actor negotiating with other international leading actors on a common code for interpreting the contingency created by the institutional aid agenda.

\subsection{Episode Three: Reshuffle (2012 - present)}

The year 2011-12 marked a paradigmatic shift in the institutional logic of aid governance [30]. The Fourth HLF in Busan, a year-long process of consultations and negotiations involving not only state actors and IOs, but also diverse stakeholders, resulted in the conclusion of the Busan Partnership Document with two significant changes. The first is the shift of focus from 'aid effectiveness' to 'development effectiveness,' namely, aid is just one of many development initiatives, such as trade and investment, where convergence is needed to create synergy. Another shift is the growing emphasis on the role of 'emerging powers' including CSOs, private sectors, and most importantly emerging non-DAC donors. These new shared understandings have become the logic of a new institutional arrangement, Global Partnership for Effective Development Cooperation (GPEDC), to be officially launched in 2014.

As the Chair of ASEAN, and the host of the South-South Cooperation High Level Meeting (Bali, 2012), Indonesia saw an opportunity to promote its leading role in the global field of aid. During the first GPEDC meeting (Mexico City, 2014), Indonesia became the Co-Chair of GPEDC along with the UK and Nigeria. As Indonesia become the leading actor in aid governance reform after 2011, the Indonesian AIMS became increasingly irrelevant in the changing environment characterized by new codification schemes to justify the legitimacy of aid governance, which stressed 
alignment with new codes such as 'aid heterogeneity' and 'emerging power'. The system was shut down in late 2012 with a part of databases moving to another unit that attempted to recycle its value for internal bureaucratic purposes for the SouthSouth cooperation. During the process in which the international community searched for new sources of legitimacy to justify the institutionalization of aid governance, the state agency of Indonesia can be clearly seen as shaping the understandings of contingent situations while simultaneously being shaped by the same international context in which it participates.

\section{Conclusion}

In this paper, we argue that understanding the failure of AIMS in Indonesia requires a shift in focus from the project's local context to the recursive relationship between the global field of aid governance and the state agency. By tracing the historical context of AIMS in Indonesia, we identify a new source of contingency, as the structureagency relationship between the macro global aid governance and Indonesia as a state which characterized by the enduring, contesting, negotiating, and collaborative relationship between the state actor and the institutional structures of aid, effectively justifies both the implementation and abandonment of the information system. Despite the fact that there had been substantial investment and coordinative efforts on the AIMS project, the eventual disuse and abandonment of AIMS is not attributable to anyone in particular. No stakeholder may be held justifiably responsible for adapting the system to the contingency caused by institutional changes in the global field of aid. Instead, all stakeholders were working together to define and implement a shifting consensus of aid governance characterized by the emerging powers and heterogenous aid partners.

This paper contributes to ICTD literature in two ways. Firstly, we shift the theorizing focus from the local to the macro contingency, which is characterized by the evolution of global aid institutions and the rising power of emerging states. Such a shift can engage ICT4D researchers in a direct critique of development discourses and international political economy. Avgerou (2008) called upon the ICTD field to develop "the epistemological capacity to associate the study of IS innovation with the particular socioeconomic and policy rationale that provides its underlying justification and targets". Future research needs to further develop in-depth critical understandings on the power struggles, particularly how those emerging economies shape the global development agenda by strategically planning, designing, and implementing IS innovations. Secondly, we highlight the "recursivity" of contingent relations and interpretations in the context of developing country. Recursive contingency is particularly useful when IS failure occurs as part of the (de-)institutionalization process, where state actors have the agency of the reflexivity to choose alternative ways of understanding, rationalizing their situations, and justifying decisions with strategic intentions. Future research in ICTD can benefit by focusing on the "recursive contingency" in which the holistic view of actions in a field and the strategic agency $[10,16]$ to challenge and change the field structure, offer new ways of understanding failure in 
developing country. We believe the recursivity of relations between developing states and the global power structure of development will be an important aspect shaping ICTD in the coming decades.

\section{Reference}

1. S. Al-Jaghoub and C. Westrup. 2003. Jordan and ICT-led development: towards a competition state? Information Technology \& People 16, 1: 93-110.

2. C. Avgerou. 2002. Information Systems and Global Diversity. Oxford.

3. C. Avgerou and G. Walsham. 2000. Information technology in context: Implementing systems in the developing world. Brookfield, VT: Ashgate Publishing.

4. C. Avgerou. 2001. The significance of context in information systems and organizational change. Information Systems Journal, 11: 43-63.

5. C. Avgerou. 2008. Information systems in developing countries: a critical research review. Journal of Information Technology 23, 3: 133-146.

6. R. Avila, S. Chak, J. Gomicki, K. Victor, S. Presley, and Et A1. 2010. Technology for Transparency: The Role of Technology and Citizen Media in Promoting Transparency, Accountability, and Civic Participation.

7. E. Baark and R. Heeks. 1999. Donor-funded information technology transfer projects: Evaluating the life-cycle approach in Chinese science and technology projects. Information Technology for Development 8,4:185-197.

8. A. O. Bada. 2002. Local Adaptations to Global Trends: A Study of an IT-Based Organizational Change Program in a Nigerian Bank. The Information Society 18, 2: 77-86.

9. T. Bartley and M. Schneiberg. 2002. Rationality and Institutional Contingency: the Varying Politics of Economic Regulation in the Fire Insurance Industry. Sociological Perspectives 45, 1: 47-79.

10. P. Bourdieu. 2005. The Social Structures of the Economy.

11. X. Deroy and S. Clegg. 2015. Back in the USSR: Introducing Recursive Contingency Into Institutional Theory. Organization Studies 36, 1: 73-90.

12. P. J. DiMaggio and W. W. Powell. 1983. The Iron Cage Revisited: Institutional Isomorphism and Collective Rationality in Organizational Fields Paul J. DiMaggio; Walter W. Powell. American Sociological Review 48, 2: 147-160.

13. Mustafa Emirbayer and Anne Mische. 1998. What Is Agency? American Journal of Sociology 103, 4: 962-1023.

14. P. B. Evans. 1992. Indian informatics in the 1980s: The changing character of state involvement. World Development 20, 1: 1-18.

15. U. Flick. 2009. An Introduction to Qualitative Research. Sage, London.

16. N. Fligstein and D. McAdam. 2011. Toward a General Theory of Strategic Action Fields. Sociological Theory 29, 1: 1-26.

17. A. Ghosh and H. Kharas. 2011. The Money Trail : Ranking Donor Transparency in Foreign Aid.

18. R. Greenwood, A. M. Diaz, S. X. Li, and J. C. Lorente. 2010. The Multiplicity of Institutional Logics and the Heterogeneity of Organizational Responses. Organization Science 21, 2: 521-539.

19. R. Greenwood, M. Raynard, F. Kodeih, E. Micelotta, and M. Lounsbury. 2011. Institutional Complexity and Organizational Responses. The Academy of Management Annals 5, 1: 317371.

20. R. Hayman. 2009. From Rome to Accra via Kigali: “Aid Effectiveness ” in Rwanda. Development Policy Review 27, 5: 581-599.

21. R Heeks. 2002. Information systems and developing countries: Failure, success, and local improvisations. The Information Society 18, 2: 101-112.

22. R. Heeks. 2002. Information Systems and Developing Countries: Failure, Success, and 
Local Improvisations. The Information Society 18, 2: 101-112.

23. D. Hindley. 1963. Foreign Aid to Indonesia and Its Political Implications. Pacific Affairs $36,2$.

24. P. T. Jaeger and K.M. Thopmson. 2003. E-government around the world. Government Information Quarterly 20: 389-394.

25. S. Krishna, S. Sahay, and G. Walsham. 2006. Managing cross-cultural issues in global software outsourcing. In Information Systems Outsourcing: Enduring Themes, New Perspectives and Global Challenges.

26. T. Lawrence, R. Suddaby, and B. Leca. 2010. Institutional Work: Actors and Agency in Institutional Studies of Organizations. ASQ, December: 673-677.

27. S. Maguire, C. Hardy, and T. Lawrence. 2004. Institutional entrepreneurship in emerging fields: HIV/AIDS treatment advocacy in Canada. Academy of Management Journal 47, 5: 657-679.

28. S. Masiero. 2015. Redesigning the Indian Food Security System through E-Governance: The Case of Kerala. World Development 67: 126-137.

29. H. Masyrafah and J. Mckeon. 2008. Post-Tsunami Aid Effectiveness in Aceh: proliferation and coordination in reconstruction. Washington DC.

30. E. Mawdsley, L. Savage, and SM Kim. 2014. A "post-aid world"? Paradigm shift in foreign aid and development cooperation at the 2011 Busan High Level Forum. Geographical Journal 180, 1: 27-38.

31. A. Moussa and R. Schware. 1992. Informatics in Africa: Lessons from World Bank experience. World Development 20, 12: 1737-1752.

32. D. Moyo. 2008. Dead Aid: Why aid is not working and how there is another way for Africa. Penguin, London.

33. OECD. 2005. Paris Declaration on the Aid Effectiveness. Paris.

34. OECD. 2008. The Paris Declaration on Aid Effectiveness and the Accra Agenda for Action. Paris.

35. K.R. Park. 2017. An Analysis of Aid Information Management Systems (AIMS) in Developing Countries: Explaining the Last Two Decades. In Proceedings of the 50th Hawaii International Conference on System Sciences.

36. B. Ramalingam. 2013. Aid on the Edge of Chaos. Journal of Chemical Information and Modeling 53, 9: 1689-1699.

37. W R. Scott. 2008. Institutions and organizations: Ideas and interests.

38. M. Sjösted. 2013. Aid effectiveness and the Paris Declaration: A mismatch between ownership and result-based management? Public Administration and Development 33, 2.

39. P. H. Thornton and W. Ocasio. 2005. Institutional Logics.

40. G. Walsham. 1993. Interpreting information systems in organizations. John Wiley \& Sons, New York.

41. R. Wittemyer, S. Bailur, N. Anand, K.R. Park, and S. Gigler. 2014. New Routes to Governance. In Closing the Feedback Loop: Can Technology Bridge the Accountability Gap? World Bank, Washington DC.

42. WorldBank and InfoDev. 2012. Information and Communications for Development 2012: Maximizing Mobile.

43. R. Yin. 2009. Case Study Research: Design and Methods. 